\title{
PENGGUNAAN TEKNIK TRANSFER PRINTING DENGAN MOTIF ILUSTRASI TOKOH BARONG REOG PONOROGO PADA BUSANA READY TO WEAR DELUXE
}

\author{
THE USING OF TRANSFER PRINTING TECHNIQUE WITH \\ BARONG ILLUSTRATION FROM REOG PONOROGO IN \\ READY TO WEAR DELUXE CLOTHING
}

\author{
Tina Martina ${ }^{1}$, Fitri Annisail Karimah ${ }^{2}$ dan Nindhita Gita P.H. ${ }^{3}$ \\ 1. Dosen Politeknik STTT Bandung, Indonesia \\ 2. Mahasiswa Politeknik STTT Bandung, Indonesia \\ 3. Staf Pengajar Politeknik STTT Bandung, Indonesia \\ Produksi Garmen, Politeknik STTT Bandung, 40272, Indonesia \\ E-mail: martina12sttt@gmail.com, fitriannisail@gmail.com,
}

herdiyaninindhita@gmail.com

\begin{abstract}
ABSTRAK
Reog Ponorogo merupakan salah satu kesenian dan budaya yang ada di Indonesia. Berasal dari kota Ponorogo, Jawa Timur, memiliki ciri khas simbol kepala singa dan burung merak. Kedua karakter yang memiliki pesan akan keberanian dalam sikap hidup masyarakatnya. Metodologi penelitian yang digunakan adalah studi pustaka dan pembuatan produk busana. Hasil produk dari penelitian ini berupa busana ready to wear deluxe yang terinspirasi dari tokoh barong Reog Ponorogo yang dibuat untuk tujuan mempertahankan kesenian dan budaya Indonesia dalam bentuk busana. Perancangan busana dalam penelitian ini menggunakan ilustrasi dari tokoh Barong dalam Reog Ponorogo yang kemudian diterapkan pada kain dengan teknik transfer printing yang akan dijadikan detail menarik pada beberapa bagian busana. Teknik transfer printing adalah teknik cetak diatas permukaan kain sintetis dengan menggunakan mesin pemanas (heatpress) untuk memindahkan pigmen zat warna dari media kertas ke media kain. Pada busana tersebut ditambahkan aplikasi fringe untuk menonjolkan dan memberikan ciri khas kesenian Reog Ponorogo. Produk yang dibuat akan ditentukan harga jual sesuai dengan perhitungan harga jual dari harga pokok produksi (HPP). Tiga busana ready to wear deluxe dianalisa kesesuaian antara harga jual dan hasil produk yang sudah dibuat menggunakan metode kualitatif dengan penyebaran kuisioner. Pada 59 orang responden, busana (1) 16,9 $\%$ menilai sesuai dengan HPP , busana (2) 40,7 \% mendekati HPP dan busana (3) $33,3 \%$ sesuai HPP bahkan 28,3\% menilai lebih tinggi dari HPP.
\end{abstract}

Kata kunci: Teknik Transfer Printing, Ilustrasi Barong Reog Ponorogo, Ready to Wear Deluxe 


\begin{abstract}
Reog Ponorogo is one of the arts and culture in Indonesia. Originally from Ponorogo, East Java, it has the distinctive symbol of the head of a lion and a peacock, both of which have a deep message of courageous attitude in the society. The methodology used in this study is literature study then product manufacturing. The results of this study are ready to wear deluxe clothings inspired by the barong character from Reog Ponorogo, which was created for the purpose of preserving Indonesian art and culture in the form of clothing. The clothes design for this study is using the illustration of the barong character from Reog Ponorogo which then applied on the fabric surface with transfer printing technique and it also becomes detailings in several parts of the clothings. Transfer printing technique is a printing technique on synthetic fabric with thermal machine (heatpress) to moved the ink pigments from paper to fabric then the clothings are added with fringe application on the clothes to accentuate and give the characteristic of Reog Ponorogo. The selling price of this product will be determined with Cost of Goods Manufactured (HPP) Calculation. Three of the products of this study which are ready to wear deluxe clothing will be analyzed for their compatibility between the selling price and the product results using the qualitative methods by distributing questionnaires. Among 59 respondents we can outlined that assessed selling price of this ready to wear deluxe clothing desgin (1) 16,9 \% relevant with cost of goods sales, design (2) 40,7\% close to cost of goods sales, design (3) 33,3 \% exactly same with the cost of goods sales, even $28,3 \%$ expect over the cost of goods sales.
\end{abstract}

Keywords: Transfer Printing Technique, Barong Illustration from Reog Ponorogo, Ready to Wear Deluxe

\section{PENDAHULUAN}

Fesyen telah membawa pengaruh besar terhadap perkembangan globalisasi dan gaya hidup. Fesyen tidak hanya tentang pakaian tetapi dapat dikatakan sebagai jati diri sesorang yang diekspresikan melalui busana yang dipakai. Busana dapat diciptakan melalui beragam konsep yang didapatkan dari berbagai macam ide atau inspirasi. Indonesia memiliki beragam kebudayaan, salah satunya adalah kesenian Reog Ponorogo yang berasal dari daerah Ponorogo, Jawa Timur.

Kesenian Reog Ponorogo khas dengan keindahan simbol kepala singa dan burung merak. Perpaduan dua jenis karakter yang berbeda yaitu singa dan burung merak tersebut menyampaikan pesan yang kuat akan keberanian dan kebersahajaan masyarakat daerah Ponorogo dalam menapaki kebenaran dengan sikap hidup yang menarik. 


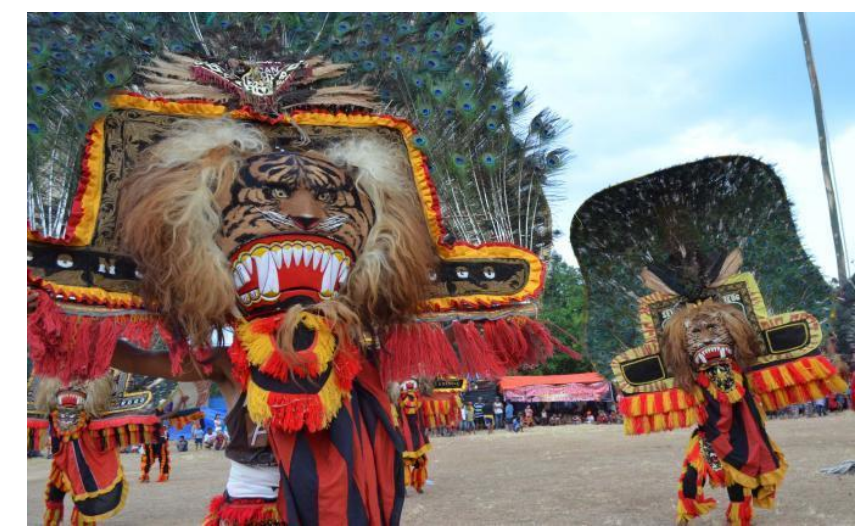

Sumber: https://www.pusakapusaka.com/sejarah-reog-ponorogo-budayaasliindonesia.html (diakses 3 Maret 2019)

\section{Gambar 1. Salah Satu Tokoh Reog Ponorogo yaitu Barong}

Menurut jurnal Andi Farid Hidayanto yang berjudul "Topeng Reog Ponorogo dalam Tinjauan Seni Tradisi” yang diterbitkan dalam jurnal Eksis Politeknik Samarinda pada Maret 2012, dikatakan bahwa sebagai seni asli Ponorogo, keberadaan Reog lambat laun tergerus oleh budaya modern yang terlihat dari semakin minimnya generasi muda yang menekuni kesenian Reog. Melihat hal tersebut, muncul inspirasi untuk mengangkat Reog Ponorogo sebagai konsep dari perancangan busana ready to wear untuk mempertahankan keberadaan kesenian Reog Ponorogo dalam simbol dan ilustrasi dalam suatu busana. Konsep perancangan busana akan mengangkat karakter tokoh Singa Barong dan Dadak Merak (penyebutan burung merak pada Reog
Ponorogo) yang dibuat dalam bentuk ilustrasi yang kemudian akan diterapkan menjadi detail aplikasi pada beberapa bagian busana.

Busana ini menerapakan reka bahan transfer printing. Reka bahan merupakan teknik atau cara yang bertujuan untuk memberikan tekstur, detail, dan volume pada material tekstil. Salah satu contoh reka bahan pada Kriya Tekstil Jilid 1 (2008) yaitu reka latar untuk mendapatkan pewarnaan dan motif adalah dengan teknik printing atau cetak. Printing merupakan salah satu teknik pewarnaan pada permukaan kain yang diproses dengan cara mekanik dan juga kimia. Hasil dari printing berbedabeda tergantung dari jenis tinta, teknik yang digunakan, dan jenis kain yang 
digunakan. Transfer printing adalah sebuah teknik cetak di atas kain sintetis dengan menggunakan panas untuk memindahkan zat warna dari media kertas ke permukaan kain. Teknik ini memaksimalkan zat warna dispersi dengan memanfaatkan sifat sublimasi dari panas dan sifat kain sintetis yang tahan panas. Transfer printing saat ini merupakan salah satu teknologi yang sedang berkembang dengan menghasilkan kain printing dengan motif dan desain khusus dalam waktu yang singkat serta detail. Proses transfer printing menggunakan printer sublime dengan printhead yang menggunakan zat warna dispersi berupa dye sublimation ink yang berbasis minyak. Printer sublime membutuhkan Software RIP (raster image processor) adalah software untuk mengelola input menjadi output sesuai dengan desain yang diinginkan. Zat warna dispersi tidak langsung dicetak ke bahan tekstil, tapi dicetak terlebih dahulu ke transfer paper kemudian dipindahkan ke kain dengan menggunakan mesin heatpress. Heatpress adalah mesin pemanas yang digunakan untuk memindahkan gambar di kertas ke bahan tekstil dengan menggunakan metoda pemanasan dan penekanan (pressing).

Busana ready to wear deluxe merupakan busana siap pakai yang memiliki konstruksi desain yang bervariatif dan tergolong rumit dibandingkan dengan busana ready to wear secara umum. Busana ready to wear deluxe umumnya memiliki teknik dan material yang khusus, serta detail yang dekoratif, seperti penggunaan reka bahan dan aplikasi tertentu untuk membuat busana lebih hidup dan menarik. Perancangan busana yang dibuat memiliki keunggulan yaitu merupakan busana deluxe atau eksklusif yang tidak diproduksi secara masal serta menggunakan teknik transfer printing dengan gambar ilustrasi barong yang masing-masing busana memiliki komposisi bagian dan bentuk gambar yang berbeda.

Penggunaan teknik transfer printing harus menggunakan kain poliester karena kain poliester memiliki daya tahan panas yang baik sehingga ketika dimasukan ke dalam mesin heatpress kain tidak meninggalkan bercak/noda kecoklatan akibat panas dari mesin heatpress. Material kain utama yang digunakan adalah canvas premium soft yang akan digunakan sebagai kain printing dari gambar ilustrasi Barong. 
Kain ini memiliki karakteristik sangat kuat, tebal, dan memiliki serat yang besar, sehingga kain ini cocok digunakan untuk aplikasi gambar yang besar.

Warna yang digunakan pada busana ready to wear deluxe ini lebih dominan kepada warna hitam yang dikombinasi dengan warna merah, putih, dan kuning, warna yang sama juga di gunakan pada fringe. Keempat warna ini merupakan warna-warna yang diambil dari ciri khas warna pada pertunjukkan Reog Ponorogo supaya busana yang dibuat tetap memiliki unsur dan ciri khas dari Reog Ponorogo.

Target pasar busana ready to wear deluxe ini adalah wanita dewasa yang memiliki pekerjaan di bidang industri fesyen dan industri entertainment, yang umumnya merupakan orang yang independent dan memiliki ketertarikan serta kecintaan pada seni dan budaya.

Berdasarkan latar belakang dan studi pustaka yang dipaparkan, maka identifikasi masalah adalah sebagai berikut:

1. Bagaimana cara mengaplikasikan ilustrasi barong pada busana ready to wear deluxe?
2. Bagaimana melakukan analisa pasar kesesuaian harga jual sesuai dengan perhitungan dengan produk busana ready to wear deluxe yang dibuat?

Maksud perancangan busana ini adalah membuat busana ready to wear deluxe yang terinspirasi tokoh Barong dari salah satu kesenian budaya Jawa Timur, Reog Ponorogo. Adapun tujuan dari perancangan busana adalah untuk mempertahankan kesenian dan budaya Indonesia dalam bentuk busana serta mengetahui bagaimana pendapat masyarakat terhadap kesesuaian harga jual dengan produk busana ready to wear deluxe yang dibuat.

Manfaat yang akan diperoleh dari hasil penelitian ini bagi para pelaku industri adalah ikut berkontribusi untuk meramaikan dunia fesyen Indonesia dengan bertambahnya perancangan busana yang terinspirasi dari kesenian dan kebudayaan di Indonesia. Bagi masyarakat umum dapat membuka wawasan tentang budaya yang ada di Indonesia, khususnya tokoh Barong dari Kesenian Reog Ponorogo.

Penelitian terdahulu yang relevan dan menjadi acuan penulisan penelitian ini adalah Perancangan Koleksi Busana 
Siap Pakai Deluxe Untuk Wanita dengan Inspirasi Simbol dan Warna Suku Zulu di Afrika (Tia Erliawati, Dewi Isma Aryani dan Indra Janty Tan ; 2018) dan penelitian yang dilakukan oleh Rizha Fauziana (2019) dengan judul Pengaruh Jenis Satin Polyester Terhadap Hasil Jadi Pewarnaan Menggunakan Teknik Heat Transfer Printing. Perbedaan dari penelitian sebelumnya adalah penggunaan Teknik Transfer Printing dengan motif Ilustrasi Tokoh Barong Reog Ponorogo pada kain drill dan baby canvas pada Busana Ready to Wear Deluxe.

\section{METODA PENELITIAN}

Penelitian ini mengunakan metode studi pustaka serta pembuatan produk. Adapun tahapan penelitian ini adalah studi pustaka tentang berbagai kajian teori yang kemudian digunakan sebagai acuan untuk membuat suatu produk. Produk yang dibuat adalah busana ready to wear deluxe atau busana siap pakai dengan menggunakan motif dengan inspirasi tokoh barong Reog Ponorogo yang akan diolah secara digital dan dicetak pada kain dengan menggunakan teknik transfer printing. Sedangkan untuk analisa pasar terhadap kesesuaian antara produk busana dengan harga jual yang didapat dari perhitungan harga jual HPP, menggunakan metode kualitatif dengan penyebaran kuisioner.

\section{HASIL DAN PEMBAHASAN}

Adapun tahapan pembuatan produk busana ready to wear deluxe adalah sebagai berikut:

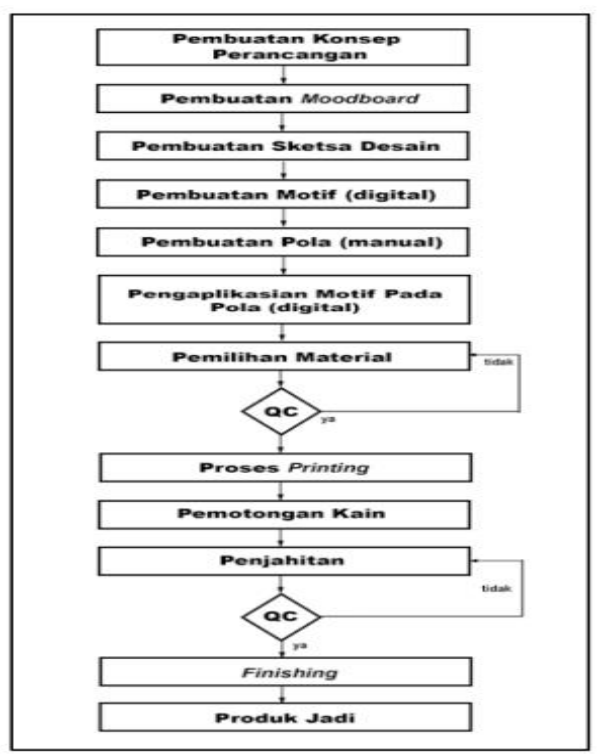

Gambar 2. Diagram Alir Pembuatan Produk Busana Ready to Wear Deluxe

Pembuatan konsep perancangan produk busana ready to wear deluxe dengan menggunakan motif yang terinspirasi dari ilustrasi tokoh Barong dan Dadak Merak dari Reog Ponorogo yang diolah secara digital dan dicetak pada kain dengan menggunakan teknik transfer printing. 
Moodboard yang dibuat untuk mempresentasikan produk pada konsep busana ready to wear deluxe berisikan tentang gambar-gambar yang berhubungan dengan tokoh utama pada kesenian Reog Ponorogo yaitu Barong. Adapun moodboard yang dibuat dapat dilihat sebagai berikut.

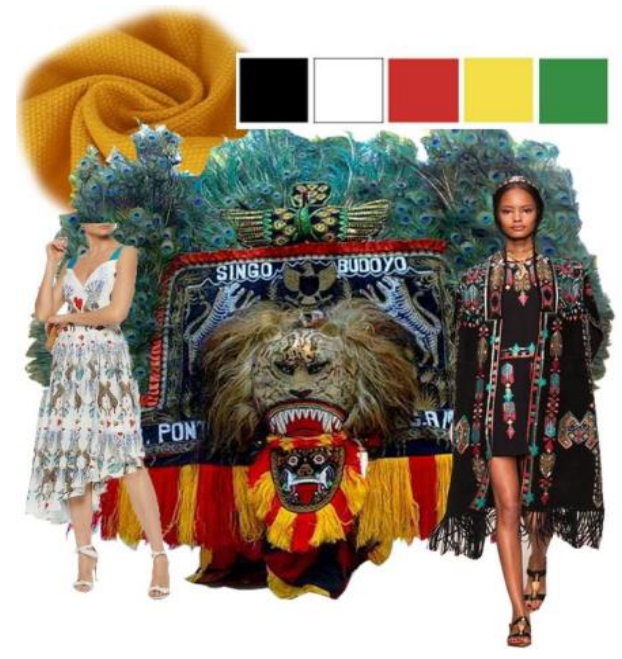

Gambar 3. Moodboard

Desain sketsa dibuat berdasarkan sumber inspirasi, moodboard, dan konsep yang yang telah ditentukan. Siluet busana yang digunakan dan diterapkan pada busana ready to wear deluxe ini adalah siluet I atau siluet persegi panjang, yaitu siluet dengan bentuk busana yang lurus, longgar dan sederhana. Desain sketsa merupakan rancangan awal yang menjadi dasar dalam pembuatan busana ready to wear deluxe yang kemudian dikembangkan kembali dan diproses menjadi 3 (tiga) buah rancangan desain busana dibuat dalam bentuk digital dan diberi warna serta motif dengan menggunakan software desain.

Desain busana ready to wear deluxe 1 , pemilihan warna didominasi dengan warna hitam yang dikombinasikan dengan perpaduan warna merah. Bentuk busana yang dibuat tegas dengan siluet lurus dan dipadukan dengan warna tersebut, dapat memberikan kesan gagah dan kuat. Point of interest pada busana terdapat pada bagian belakang busana, yaitu terdapat gambar ilustrasi Barong dengan fringe warna kuning merah yang menonjol.

Desain busana ready to wear deluxe 2, pemilihan warna didominasi dengan warna hitam yang dikombinasikan dengan perpaduan warna putih. Point of interest pada busana terdapat pada bagian samping kiri depan dan samping kiri belakang busana, yaitu terdapat gambar ilustrasi Barong cukup besar yang gambarnya saling menyatu antara setengah bagian depan dengan setangah bagian belakangnya. Selain itu, dikombinasi dengan fringe warna kuning merah 
yang sangat khas Reog pada bagian bawah busana.

Desain busana ready to wear deluxe 3, pemilihan warna didominasi dengan warna hitam yang dikombinasikan dengan perpaduan warna kuning. Bentuk busana dibuat sedikit berbeda dengan bentuk asimetris yang bertujuan untuk memberikan kesan lembut dibalik gagahnya tokoh Barong. Point of interest pada busana terdapat pada bagian tengah depan busana, yaitu terdapat gambar ilustrasi Barong yang saling membelah menjadi bagian kanan dan kiri yang menyatu.

Hasil sketsa digital desain busana dapat dilihat pada gambar berikut ini.

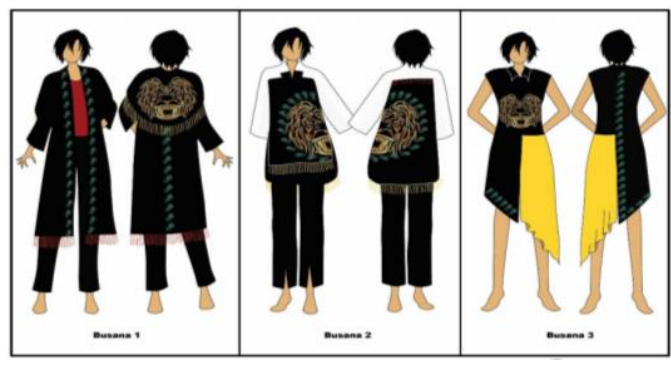

Gambar 4. Sketsa Digital Desain

Busana

Proses reka bahan pada pembuatan busana ready to wear deluxe ini adalah dengan menggunakan teknik transfer printing. Setelah proses perancangan desain digital, dilakukan proses produksi yang mencakup pembuatan motif digital, pembuatan pola manual, pengaplikasian motif pada pola digital, proses printing, pemotongan kain serta proses penjahitan dan finishing. Pembuatan gambar motif dilakukan dengan menggunakan software Adobe Illustrator CC 2017 yang kemudian dilakukan eksplorasi warna terhadap gambar digital pada warna asli tokoh Barong. Bentuk gambar ilustrasi Barong yang telah dibuat dapat dilihat pada gambar di bawah ini.

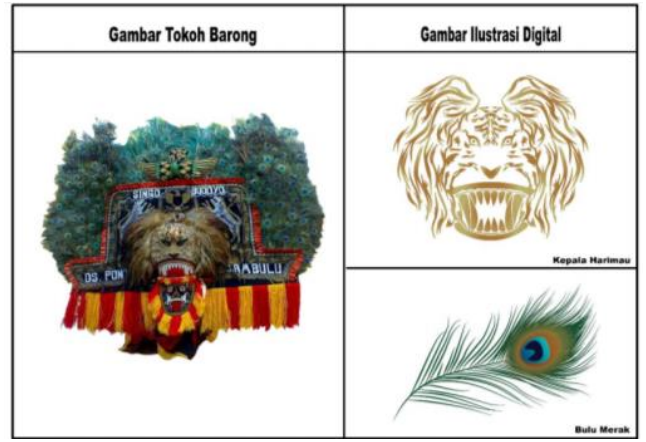

Gambar 5. Ilustrasi Tokoh Barong

Pembuatan pola dalam bentuk digital yang mana pola digital tersebut nantinya akan langsung diberi gambar motif digital untuk dilakukan proses printing. Gambar bagian pola digital dengan pemberian gambar motif dapat dilihat pada gambar berikut ini. 


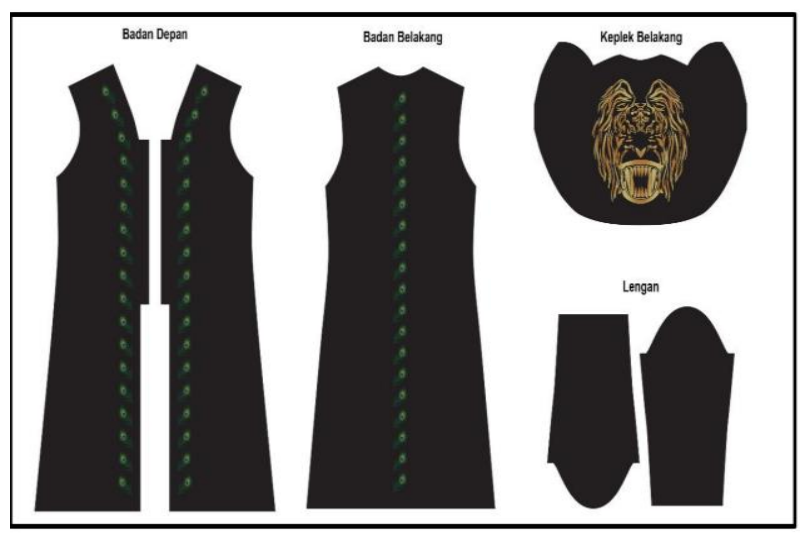

(i) Pola Busana 1

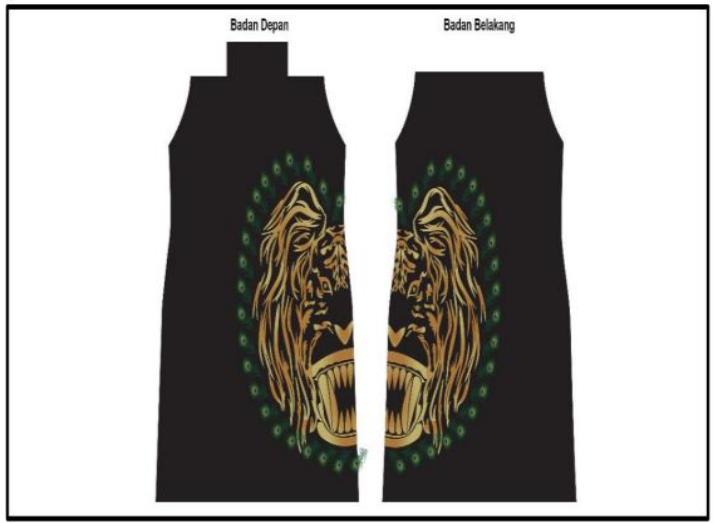

(ii) Pola Busana 2

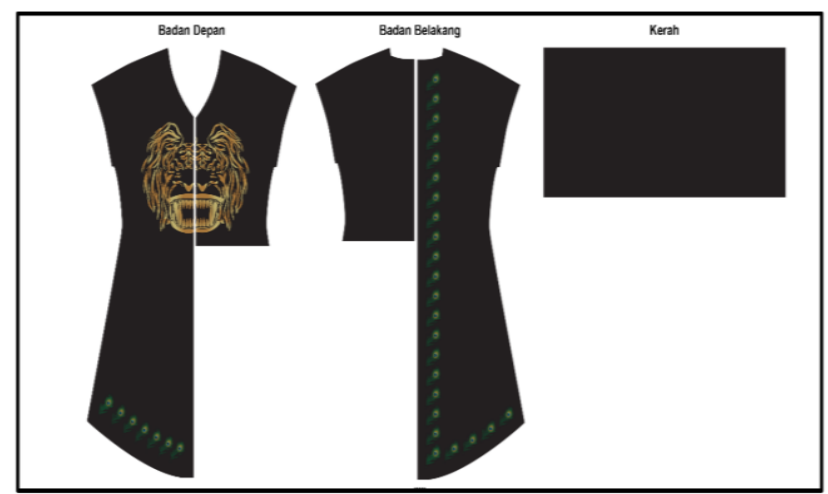

(iii) Pola Busana 3

Gambar 6. Bagian Aplikasi Motif pada Pola Digital

Pemilihan material mempertimbangkan sifat kain yang akan digunakan agar busana yang dibuat sesuai dengan desain yang dibuat. Bahan utama yang digunakan pada busana ready to wear deluxe ini adalah kain drill, kain baby canvas, dan kain canvas premium soft sebagai bahan utama yang digunakan sebagai printing motif. Bahan ini digunakan sebagai bahan untuk printing kain karena kain ini memiliki sensasi dingin dan halus ketika 
digunakan. Keunggulan canvas Pemilihan bahan yang premium soft dibanding canvas lainnya mempertimbangkan sifat kain adalah warnanya yang paling cerah berdasarkan pada pengujian langsai dan detail gambar printing yang paling (drape) kain, dengan hasil pengujian terlihat.

pada tabel berikut ini.

Tabel 1. Hasil Pengujian Langsai (Drape) Kain

\begin{tabular}{llcc}
\hline & & \multicolumn{2}{c}{ Drape Tester } \\
\cline { 3 - 4 } No. & \multicolumn{1}{c}{ Contoh Uji } & Bagian Muka & $\begin{array}{c}\text { Bagian } \\
\text { Belakng }\end{array}$ \\
\cline { 3 - 4 } & & $75,97 \%$ & $83,38 \%$ \\
2. & Canvas premium soft (printing) & $68,97 \%$ & $71,65 \%$ \\
3. $\quad$ Baby Canvas & $55,52 \%$ & $75,97 \%$ \\
\hline
\end{tabular}

Keterangan :

Pada hasil pengujian untuk kelangsaian (drape) kain dapat dilihat dari hasil persentase yang didapat. Semakin kecil nilai persentase drape, maka kain akan semakin langsai.

Dari hasil pengujian menunjukkan bahwa kain canvas premium soft merupakan kain yang paling langsai dibandingkan dengan kain drill dan kain baby canvas. Sedangkan kain drill merupakan kain yang paling kaku dibandingkan dengan kain canvas premium soft dan kain baby canvas.

Proses printing yang dilakukan dengan menggunakan teknik transfer printing adalah memindahkan hasil motif yang telah dibuat ke dalam software khusus yang digunakan oleh mesin transfer paper, setelah motif dipindahkan kedalam sofware kemudian motif dicetak kedalam kertas khusus. Selanjutnya memindahkan hasil cetak di kertas ke media kain dengan menggunakan mesin heatpress. Kain diletakkan di atas kertas motif lalu kemudian dimasukan ke dalam mesin heatpress sehingga motif pada media kertas berpindah pada media kain.

Hasil dari proses dengan teknik printing berbeda-beda tergantung dari 
jenis tinta, teknik yang digunakan, dan jenis kain yang digunakan. Oleh karena itu untuk teknik transfer printing perlu dilakukan pengujian dari hasil printing dengan teknik transfer printing. Maksud dari dilakukannya pengujian adalah untuk memperkuat data bahwa teknik transfer printing pada kain memiliki daya tahan cuci yang baik. Pengujian yang dilakukan berdasarkan SNI ISO 105 - C 06: 2010 adalah pengujian ketahanan luntur warna kain terhadap pencucian, gosokan, dan keringat.

Tabel 2. Hasil Pengujian Ketahanan Luntur Warna Kain Canvas Premium Soft

\begin{tabular}{|c|c|c|c|c|c|c|c|c|}
\hline \multirow{3}{*}{$\begin{array}{l}\text { Contoh } \\
\text { Uji }\end{array}$} & \multicolumn{3}{|c|}{ Pencucian } & \multicolumn{2}{|c|}{ Gosokan } & \multicolumn{3}{|c|}{ Keringat } \\
\hline & \multicolumn{2}{|c|}{ Staining Scale } & \multirow[b]{2}{*}{$\begin{array}{l}\text { Gray } \\
\text { Scale }\end{array}$} & \multicolumn{2}{|c|}{ Staining Scale } & \multicolumn{2}{|c|}{ Staining Scale } & \multirow{2}{*}{$\begin{array}{l}\text { Gray } \\
\text { Scale }\end{array}$} \\
\hline & $\begin{array}{l}\text { Kain } \\
\text { Rayon }\end{array}$ & $\begin{array}{c}\text { Kain } \\
\text { Poliester }\end{array}$ & & $\begin{array}{c}\text { Kain } \\
\text { Rayon }\end{array}$ & $\begin{array}{c}\text { Kain } \\
\text { Poliester }\end{array}$ & $\begin{array}{c}\text { Kain } \\
\text { Rayon }\end{array}$ & $\begin{array}{c}\text { Kain } \\
\text { Poliester }\end{array}$ & \\
\hline$A$ & 5 & 5 & 5 & - & - & - & - & - \\
\hline$B$ & 5 & 5 & 5 & - & - & - & - & - \\
\hline$C$ & - & - & - & 5 & 5 & - & - & - \\
\hline D & - & - & - & 5 & 5 & - & - & - \\
\hline $\begin{array}{l}\text { E+larutan } \\
\text { asam }\end{array}$ & - & - & - & - & - & 4 & 5 & 5 \\
\hline $\begin{array}{l}\text { E+larutan } \\
\text { basa }\end{array}$ & - & - & - & - & - & 5 & 5 & 5 \\
\hline
\end{tabular}

Teknik transfer printing pada kain canvas premium soft menunjukkan ketahanan luntur warna yang baik sekali terhadap pencucian, gosokan, dan keringat.

Tabel 3. Hasil Pengujian Ketahanan Luntur Warna Kain Drill

\begin{tabular}{|c|c|c|c|c|c|c|c|c|}
\hline \multirow{3}{*}{$\begin{array}{l}\text { Contoh } \\
\text { Uji }\end{array}$} & \multicolumn{3}{|c|}{ Pencucian } & \multirow{2}{*}{\multicolumn{2}{|c|}{$\begin{array}{c}\text { Gosokan } \\
\text { Staining Scale }\end{array}$}} & \multicolumn{3}{|c|}{ Keringat } \\
\hline & \multicolumn{2}{|c|}{ Staining Scale } & \multirow[b]{2}{*}{$\begin{array}{l}\text { Gray } \\
\text { Scale }\end{array}$} & & & \multicolumn{2}{|c|}{ Staining Scale } & \multirow[b]{2}{*}{$\begin{array}{l}\text { Gray } \\
\text { Scale }\end{array}$} \\
\hline & $\begin{array}{l}\text { Kain } \\
\text { Rayon }\end{array}$ & $\begin{array}{c}\text { Kain } \\
\text { Poliester }\end{array}$ & & $\begin{array}{l}\text { Kain } \\
\text { Rayon }\end{array}$ & $\begin{array}{c}\text { Kain } \\
\text { Poliester }\end{array}$ & $\begin{array}{l}\text { Kain } \\
\text { Rayon }\end{array}$ & $\begin{array}{c}\text { Kain } \\
\text { Poliester }\end{array}$ & \\
\hline$A$ & 4 & 5 & $4 / 5$ & - & - & - & - & - \\
\hline$B$ & 4 & 5 & $4 / 5$ & - & - & - & - & - \\
\hline C & - & - & - & 4 & 3 & - & - & - \\
\hline D & - & - & - & $4 / 5$ & 3 & - & - & - \\
\hline $\begin{array}{l}\text { E+larutan } \\
\text { asam }\end{array}$ & - & - & - & - & - & $3 / 4$ & 5 & $4 / 5$ \\
\hline $\begin{array}{l}\text { E+larutan } \\
\text { basa }\end{array}$ & - & - & - & - & - & $4 / 5$ & 5 & $4 / 5$ \\
\hline
\end{tabular}


Teknik transfer printing pada kain drill menunjukkan ketahanan luntur warna yang baik terhadap pencucian, gosokan, dan keringat.

Tabel 4. Hasil Pengujian Ketahanan Luntur Warna Kain Baby Canvas

\begin{tabular}{|c|c|c|c|c|c|c|c|c|}
\hline \multirow{3}{*}{$\begin{array}{l}\text { Contoh } \\
\text { Uji }\end{array}$} & \multicolumn{3}{|c|}{ Pencucian } & \multirow{2}{*}{\multicolumn{2}{|c|}{$\begin{array}{c}\text { Gosokan } \\
\text { Staining Scale }\end{array}$}} & \multicolumn{3}{|c|}{ Keringat } \\
\hline & \multicolumn{2}{|c|}{ Staining Scale } & \multirow[b]{2}{*}{$\begin{array}{l}\text { Gray } \\
\text { Scale }\end{array}$} & & & \multicolumn{2}{|c|}{ Staining Scale } & \multirow[b]{2}{*}{$\begin{array}{l}\text { Gray } \\
\text { Scale }\end{array}$} \\
\hline & $\begin{array}{l}\text { Kain } \\
\text { Rayon }\end{array}$ & $\begin{array}{c}\text { Kain } \\
\text { Poliester }\end{array}$ & & $\begin{array}{c}\text { Kain } \\
\text { Rayon }\end{array}$ & $\begin{array}{c}\text { Kain } \\
\text { Poliester }\end{array}$ & $\begin{array}{c}\text { Kain } \\
\text { Rayon }\end{array}$ & $\begin{array}{c}\text { Kain } \\
\text { Poliester }\end{array}$ & \\
\hline$A$ & $4 / 5$ & 5 & $4 / 5$ & - & - & - & - & - \\
\hline$B$ & $4 / 5$ & 5 & $4 / 5$ & - & - & - & - & - \\
\hline C & - & - & - & $4 / 5$ & 4 & - & - & - \\
\hline $\mathrm{D}$ & - & - & - & $4 / 5$ & 4 & - & - & - \\
\hline $\begin{array}{l}\text { E+larutan } \\
\text { asam }\end{array}$ & - & - & - & - & - & 4 & 5 & $4 / 5$ \\
\hline $\begin{array}{l}\text { E+larutan } \\
\text { basa }\end{array}$ & - & - & - & - & - & $4 / 5$ & 5 & $4 / 5$ \\
\hline
\end{tabular}

Teknik transfer printing pada kain baby canvas menunjukkan ketahanan luntur warna yang baik terhadap pencucian, gosokan, dan keringat.

Proses pemotongan dilakukan secara manual dengan mengguakan alat bantu seperti gunting kain, pita ukur, jarum pentul, dan pemberat kain. Proses pemotongan harus dilakukan pada bidang datar supaya potongan yang dihasilkan sesuai dengan bentuk pola yang dibuat. Sebelum dilakukan proses pemotongan, terlebih dahulu pola busana ditata dan disusun diatas kain dengan memperhatikan arah serat kain, ukuran kampuh, dan gambar motif pada kain.

Proses penjahitan dilakukan untuk menggabungkan komponen- komponen kain berdasarkan hasil pemotongan sesuai pola busana secara manual dengan menggunakan jahitan tangan atau mesin dengan menggunakan mesin jahit. Pengendalian mutu proses yang dilakukan adalah dengan cara mengecek busana secara menyeluruh yang telah dijahit untuk memastikan tidak adanya cacat. Berupa pengecekan cacat pada jahitan, cacat pada bentuk komposisi atau ukuran busana, dan kesesuain benang jahit dengan kain yang dijahit. 
Pada proses finishing dilakukan proses trimming pembersihan sisa benang, proses steaming menggunakan setrika uap atau setrika gosok dan proses penambahan aplikasi pada busana dengan menggunakan jahitan tangan.
Produk busana ready to wear deluxe hasil dokumentasi produk dapat dilihat pada gambar berikut.

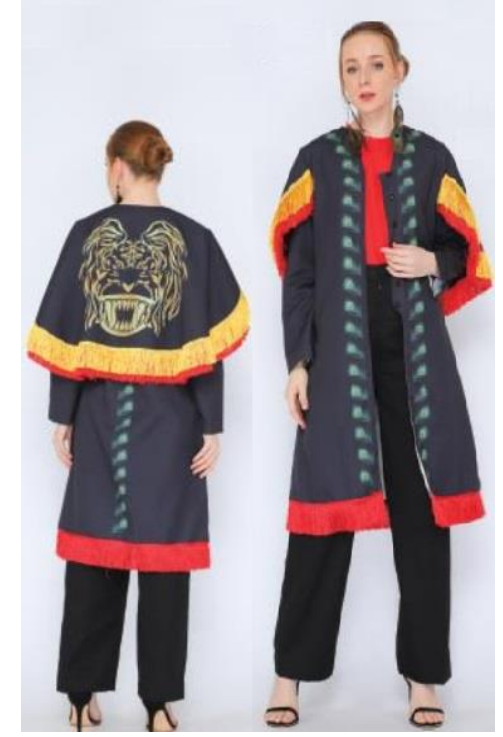

(i) Busana 1

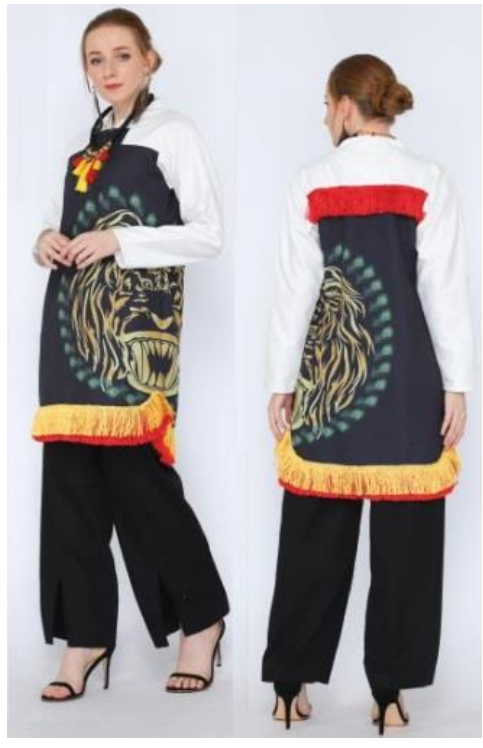

(ii) Busana 2

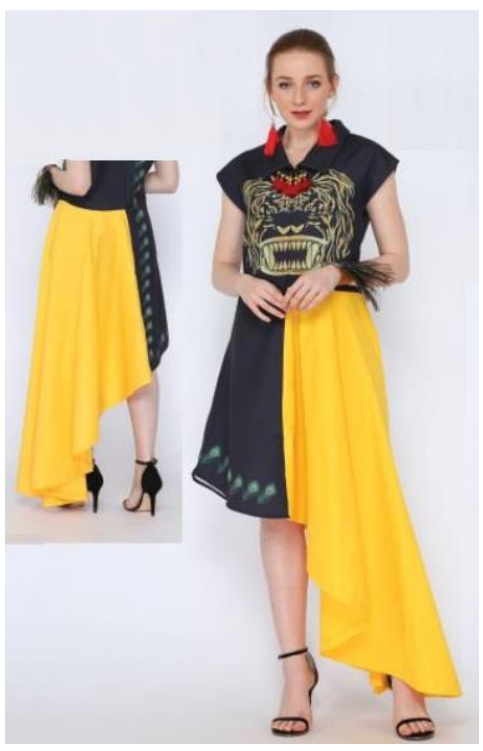

(iii) Busana 3

Gambar 7. Dokumentasi Produk Busana Ready to Wear Deluxe

Perhitungan biaya produksi dilakukan untuk mengetahui seluruh biaya yang dikeluarkan dalam proses produksi yang disebut dengan Harga Pokok Produksi (HPP). HPP yang sudah diketahui selanjutnya dapat digunakan untuk menentukan harga jual produk busana yang sesuai dengan laba yang diinginan dan target pasar yang dituju.
Busana 1 terdiri dari dua buah baju, yang tediri dari celana dan outer. Busana 2 terdiri dari dua buah baju, yang tediri dari blus dan celana. Busana 3 terdiri dari satu buah baju, yaitu atasan selutut. Adapun perhitungan biaya produksi dan harga jual berikut ini. 
Tabel 5. Perhitungan Biaya Bahan Baku

\begin{tabular}{lrrr}
\hline \multirow{2}{*}{ No. Nama Bahan } & \multicolumn{3}{c}{ Harga (Rp) } \\
\cline { 2 - 4 } & Busana 1 & Busana 2 & Busana 3 \\
\hline Bahan Utama & & & \\
1. Canvas premium soft (printing & 325.000 & 130.000 & 195.000 \\
$\quad \begin{array}{rlr}\text { outer) } \\
\text { 2. Canvas premium soft (polos) }\end{array}$ & & 55.000 & \\
3. Drill (celana) & 42.900 & 42.900 & \\
4. Baby Canvas & & & 35.000 \\
Bahan Pendukung dan Aplikasi & & & \\
5. Kancing, Zipper, Tricot, Fringe & 71.500 & 37.500 & 5.000 \\
Total biaya bahan baku & 439.400 & 265.400 & 235.000 \\
\hline
\end{tabular}

Tabel 6. Perhitungan Biaya Tenaga Kerja

\begin{tabular}{llrrr}
\hline \multirow{2}{*}{ No. } & Uraian & \multicolumn{3}{c}{ Harga (Rp) } \\
\cline { 2 - 5 } & Busana 1 & Busana 2 & Busana 3 \\
\hline 1. & Jasa Desain & 100.000 & 100.000 & 100.000 \\
2. Jasa Penjahitan & 300.000 & 300.000 & 200.000 \\
Total biaya tenaga kerja & 400.000 & 400.000 & 300.000 \\
\hline
\end{tabular}

Tabel 7. Perhitungan Biaya Overhead

\begin{tabular}{crrrr}
\hline \multirow{2}{*}{ No. Uraian } & \multicolumn{3}{c}{ Harga (Rp) } \\
\cline { 2 - 5 } & Busana 1 & Busana 2 & \multicolumn{1}{c}{ Busana 3 } \\
\hline 1. & Biaya photoshoot (model, & 200.000 & 200.000 & 200.000 \\
& studio, photographer, editing) & 6.000 & 6.000 & 6.000 \\
2. & Hanger & 32.500 & 12.500 & 32.500 \\
3. Cover dress & 238.500 & 218.500 & 238.500 \\
\hline
\end{tabular}

Tabel 8. Perhitungan Harga Pokok Produksi (HPP)

\begin{tabular}{crrrr}
\hline \multirow{2}{*}{ No. } & \multirow{2}{*}{ Keterangan } & \multicolumn{3}{c}{ Harga (Rp) } \\
\cline { 2 - 5 } & Busana 1 & Busana 2 & Busana 3 \\
\hline 1. & Biaya Bahan Baku & 439.400 & 265.400 & 235.000 \\
2. & Biaya Tenaga Kerja & 400.000 & 400.000 & 300.000 \\
3. & Biaya Overhead & 238.500 & 218.500 & 238.500 \\
Total HPP & 1.077 .900 & 883.900 & 773.500 \\
\hline
\end{tabular}

Tabel 9. Perhitungan Harga Jual Busana

\begin{tabular}{crrrr}
\hline \multirow{2}{*}{ No. } & \multirow{2}{*}{ Uraian } & \multicolumn{3}{c}{ Harga (Rp) } \\
\cline { 2 - 5 } 1. HPP & 1.077 .900 & \multicolumn{1}{c}{ Busana 2 } & \multicolumn{1}{c}{ Busana 3 } \\
2. Laba (50\% x HPP) & 538.950 & 441.950 & 773.500 \\
Harga Jual Busana (HPP + Laba) & 1.616 .850 & 1.325 .850 & 1.160 .650 \\
\hline Harga Jual yang dibulatkan & 1.700 .000 & 1.400 .000 & 1.200 .000 \\
\hline
\end{tabular}


Target pasar atau customer profile untuk busana ready to wear deluxe terinspirasi tokoh Barong dengan menggunakan teknik transfer printing adalah wanita berusia 25-40 tahun yang memiliki pekerjaan di dunia hibur, industri fesyen dan kesenian yang memiliki ketertarikan terhadap busana fesyen wearable art. Customer untuk busana ini merupakan kategori wanita yang stylist, berjiwa independent, serta merupakan seseorang yang memiliki ketertarikan dan kecintaan terhadap seni dan budaya. Pada umumnya customer ini tinggal di kota-kota besar dengan kelas ekonomi menengah ke atas.

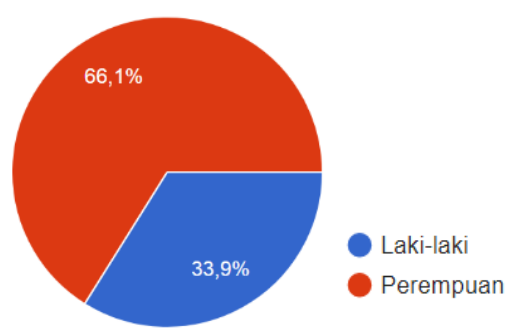

(i) Jenis Kelamin

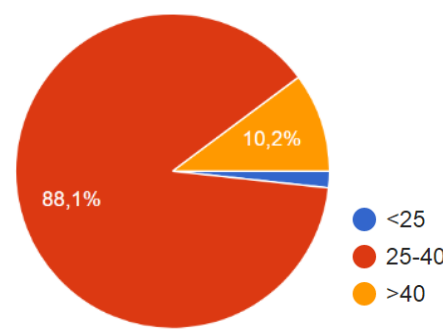

(ii) Usia (tahun)

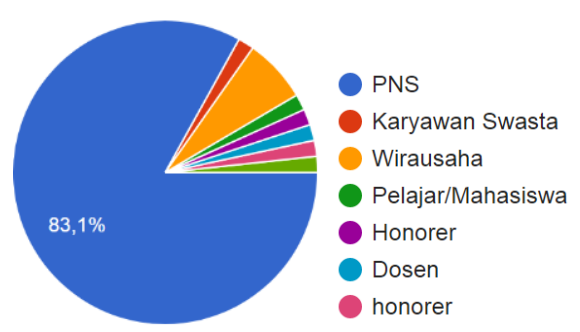

(iii) Pekerjaan

Harga jual ditetapkan dengan target pangsa pasar yang dibidik. Berdasarkan pangsa pasar yang telah ditentukan, harga jual produk busana ready to wear deluxe yang telah ditetapkan untuk busana $1 R p$ 1.700.000,00; untuk busana $2 \mathrm{Rp}$ 1.400.000,00; dan untuk busana $3 \mathrm{Rp}$ 1.200.000,00. Kemudian disebarkan kuisioner kesesuaian harga jual dengan produk yang dihasilkan. Hasil kuisioner dapat dilihat dari diagram berikut ini.

Gambar 8. Informasi singkat responden.

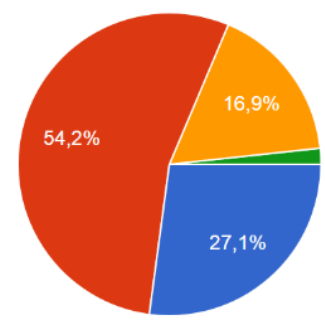

(i) Busana 1

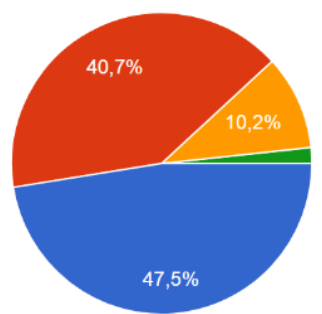

(ii) Busana 2

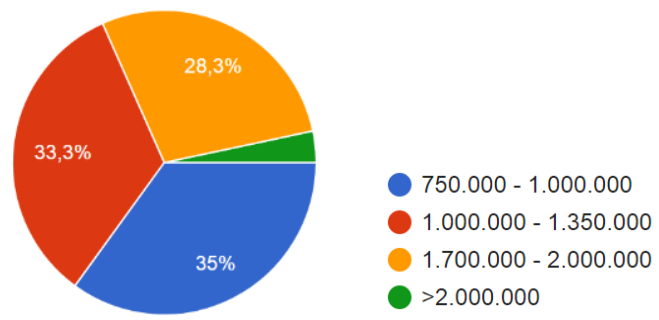

(iii) Busana 3

Gambar 9. Kesesuaian Harga Jual dengan Busana Ready to Wear Deluxe Menurut Responden 
Jumlah responden yang mengisi kuisioner ada 59 orang dengan berbagai pekerjaan dan sebagian besar berada pada rentang usia 25-40 tahun. Menurut responden busana 1 lebih sesuai apabila diberikan harga jual Rp 1.000.000 - Rp 1.350.000, hal ini menunjukkan penilaian harga jual dari responden lebih rendah dari harga jual perhitungan HPP yaitu Rp 1.700.000. Menurut responden busana 2 lebih sesuai apabila diberikan harga jual Rp 750.000 - Rp 1.000.000, hal ini menunjukkan penilaian harga jual dari responden lebih rendah dari harga jual perhitungan HPP yaitu Rp 1.400.000. Menurut responden busana 3 lebih sesuai apabila diberikan harga jual $\mathrm{Rp}$ 750.000 - Rp 1.000.000, hal ini menunjukkan penilaian harga jual dari responden lebih rendah dari harga jual perhitungan HPP yaitu Rp 1.200.000. Tetapi secara keseluruhan responden menilai harga jual busana $1>$ harga jual busana $2>$ harga jual busana 3 , sesuai dengan rentang harga jual yang dihitung dengan HPP yaitu: harga jual busana $1>$ harga jual busana $2>$ harga jual busana 3 . Penilaian masyarakat yang lebih rendah dari HPP karena pemahaman masyarakat tentang proses transfer printing dan aplikasi busana berupa fringe yang termasuk wearable art masih bersifat random begitu juga dengan minat terhadap wearable art yang kemungkinan masih belum banyak. Harga pokok produksi yang sedikit lebih tinggi dari penilaian masyarakat juga dapat disebabkan karena peneliti memasukan unsur biaya pemotretan dan laba yang terlalu besar bagi desainer pemula yang belum mempunyai pangsa pasar di masyarakat umum.

\section{KESIMPULAN}

Berdasarkan hasil penelitian berupa pembuatan produk, dapat disimpulkan beberapa hal, yaitu:

1. Pengaplikasian tokoh barong pada busana ready to wear deluxe ini adalah dengan membuat gambar ilustrasi dari tokoh barong tersebut. Pengaplikasian ilustrasi barong pada busana ready to wear deluxe sebagai motif busana adalah dengan menggunakan teknik transfer printing. Teknik cetak diatas kain dengan menggunakan mesin pemanas (heatpress) untuk memindahkan 
pigmen zat warna dari media kertas ke media kain.

2. Penetapan harga jual busana ready to wear deluxe ini dilakukan dengan menghitung harga pokok produksi atau HPP ditambah dengan laba. Analisis kesesuaian antara harga jual dan hasil produk yang sudah dibuat menggunakan metode kualitatif dengan penyebaran kuisioner menghasilkan penilaian masyarakat yang lebih rendah dibandingkan dengan HPP.

Pada 59 orang responden, busana (1) $16,9 \%$ menilai sesuai dengan HPP, busana (2) $40,7 \%$ mendekati HPP dan busana (3) 33,3\% sesuai HPP bahkan $28,3 \%$ menilai lebih tinggi dari HPP.

\section{DAFTAR PUSTAKA}

1. Alex Hidayat. 2018. Modul Materi Mk Merchandising. Bandung: Politeknik STTT Bandung

2. Budiyono dkk. 2008. Kriya Tekstil Jilid 1. Jakarta: Direktorat Pembinaan Sekolah Menengah Kejuruan.

3. Soeparman, S., Dr.N.M.Surdia, M., Budiarti, M., \& Hendrodyantopo, S. 1977. Teknologi Penyempurnaan Tekstil. Bandung: Intitut Teknologi Tekstil.

4. Susyami Hitariat, Widayat, \& Totong. 2005. Bahan Ajar Praktek Evaluasi Kain. Bandung: Politeknik STTT Bandung.

5. Wibowo Moerdoko, S., Isminingsih, M., Wagimun, S., \& Soeripto, B. 1973. Evaluasi Tekstil Bagian Fisika. Bandung: Institut Teknologi Tekstil.

6. Andi Farid Hidayanto. 2019. Topeng Reog Ponorogo Dalam Tinjauan Seni Tradisi. Diambil kembali dari Jurnal Eksis: http://karyailmiah.polnes.ac.id/Download-PDF/EKSIS-VOL.08-NO.1 -APRIL2012/No\%2017\%20-\%20andi\%20farid\%20-\%202133\%20-\%202138\%20-\%20 TOPENG\%20REOG\%20PONOROGO\%20DALAM\%20TINJAUAN\%20 SENI\%20TRADISI.pdf

7. Mazharul Islam Kiron. 2019. Transfer Printing Process. Diakses: Maret 2019. https://textilelearner.blogspot.com/2012/03/transfer-printing-process.html 
8. Rizha Fauziana. 2019. Pengaruh Jenis Satin Polyester Terhadap Hasil Jadi Pewarnaan Menggunakan Teknik Heat Transfer Printing. Diambil kembali dari https://jurnalmahasiswa.unesa.ac.id/index.php/jurnal-tatabusana/article/view/26721/24455

9. Stefan William. 2019. Sejarah Reog Ponorogo Budaya Asli Indonesia.

Diambil kembali dari pusakapusaka.com Keunikan \& Kekayaan Indonesia: https://www.pusakapusaka.com/sejarah-reog-ponorogo-budayaasliindonesia.html

10. Tia Erliawati, Dewi Isma Aryani dan Indra Janty Tan. 2018. Perancangan Koleksi Busana Siap Pakai Deluxe Untuk Wanita dengan Inspirasi Simbol dan Warna Suku Zulu di Afrika. Diambil kembali dari https://core.ac.uk/download/pdf/229638968.pdf

11.SNI ISO 105 - C 06 : 2010: Kain - Cara Uji Tahan Luntur Warna - Gosokan 12.SNI ISO 105 - E04 : 2010: Tekstil - Cara Uji Tahan Luntur Warna - Bagian E04 : Tahan Luntur Warna Terhadap Keringat

13.SNI 08-1511-1989: Cara Uji Kelangsaian Kain

14.SNI 08-6332-2000: Cara Uji Kelangsaian Kain Secara Digital. 